\title{
Inhibition of Copper Corrosion in 1 M Nitric Acid - Electro Analytical and Theoretical Study with (E)-(4-(4-Methoxybenzylideneamino)-4H-1, 2, 4-Triazole-3, 5- diyl) Dimethanol (MBATD)
}

\author{
Bincy Joseph and Abraham Joseph ${ }^{*}$ \\ Department of Chemistry, University of Calicut, \\ P.O, 673635, Kerala, India
}

Received 21 February 2011; accepted 14 June 2011

\begin{abstract}
The inhibition of copper corrosion in $1 \mathrm{M} \quad \mathrm{HNO}_{3}$ by (E)-(4-(4methoxybenzylideneamino)-4H-1, 2, 4-triazole-3, 5-diyl) dimethanol (MBATD) was investigated by polarization, ac impedance, adsorption studies, quantum chemical calculations, molecular dynamics methods and surface morphological studies. Polarization studies showed that MBATD acts as a mixed type inhibitor. Adsorption followed the Langmuir isotherm with negative value of free energy. Various thermodynamic and kinetic parameters were calculated to understand the energy changes associated during the inhibition process. The correlation between inhibitive effect and molecular structure is ascertained by quantum chemical calculations using density functional theory and Fukui functions. The molecular dynamics method has also been used to simulate the adsorption of inhibitor molecule on the metal surface.
\end{abstract}

Keywords: copper, acid solutions, EIS, polarization, acid inhibition.

\section{Introduction}

Copper metal plays vital roles in chemical and microelectronic fields due to its high thermal conductivity, electrical conductivity and low cost. It requires strong oxidants for corrosion or dissolution. Nitric acid is one of the most widely used corrosive medium that attracted a great deal of research on copper corrosion [1, 2]. One of the most practical and popular methods for protecting metals against corrosion is the use of inhibitors. Most of the acid corrosion inhibitors are nitrogen, sulphur and or oxygen containing organic compounds. Among these compounds, $\mathrm{N}$-based heterocyclic compounds are found to be efficient inhibitors for copper in acid solutions [3-7].

\footnotetext{
* Corresponding author. E-mail address: drabrahamj@gmail.com
} 
Quantum-chemical calculations have been found to be quite useful to investigate the reaction mechanisms of the inhibitor molecule and its electronic states $[8,9]$. The geometry of the inhibitor molecule in its ground state, nature of its molecular orbital like highest occupied molecular orbital (HOMO) and lowest unoccupied molecular orbital (LUMO), are involved in the inhibition activity. Through DFT calculations it is possible to correlate inhibition property with ionization potential $(\mathrm{I})$, electron affinity $(\mathrm{A})$ and number of electrons transferred $(\Delta \mathrm{N})$. Molecular dynamics simulation studies unveil the mechanism of corrosion inhibition through interaction of molecules with surface metal atoms [10-13].

This paper describes the corrosion inhibition efficiency of (E)-(4-(4methoxybenzylideneamino)-4H-1, 2, 4-triazole-3, 5-diyl) dimethanol (MBATD) towards copper in $1 \mathrm{M}$ nitric acid at various concentrations $(25,50,100$ and 200 ppm) and temperatures (303-323 K) using polarization, electrochemical impedance spectroscopy (EIS), quantum chemical calculations, adsorption studies and surface morphological studies. The thermodynamic functions and activation parameters for the adsorption process were calculated and discussed. In addition, an attempt has also been made to investigate the adsorption of MBATD molecule on the copper (110) surface using molecular dynamics simulations.

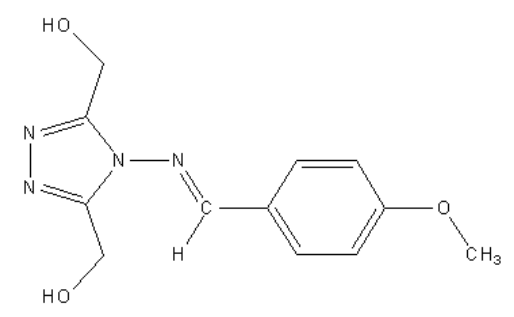

Figure 1. Structure of the inhibitor molecule (MBATD).

\section{Experimental}

\section{Inhibitor}

The method adopted for the preparation of 1, 2, 4-triazole precursor, 4-amino4H-1, 2, 4-triazole-3, 5-dimethanol (ATD) is the condensation of glycolic acid with hydrazine hydrate. Hydrazine monohydrate (E. Merck) (3.75 g, $0.75 \mathrm{~mol}$ ) was added drop wise $8{ }^{\circ} \mathrm{C}$ to $70 \%$ aqueous glycolic acid (E. Merck) $(54.3 \mathrm{~g}, \mathrm{v}$ $0.50 \mathrm{~mol})$. The resulting solution was heated at $120{ }^{\circ} \mathrm{C}$ for $6 \mathrm{~h}$. Then the reflux condenser was replaced with a downward condenser and the reaction mixture was heated at $160{ }^{\circ} \mathrm{C}$ for a further $18 \mathrm{~h}$ allowing excess hydrazine and water to distil off. After cooling, the yellowish crystalline solid obtained was recrystallized from water to give analytically pure ATD. MBATD was prepared by the condensation of ATD with p-methoxy benzaldehyde (E.Merck) (1:1 molar ratio) using alcohol as the solvent [14-16]. The compound is soluble in $1 \mathrm{M}$ $\mathrm{HNO}_{3}$ at room temperature. The structure of the compound is given in Fig 1. (Molecular formula- $\mathrm{C}_{12} \mathrm{H}_{14} \mathrm{~N}_{4} \mathrm{O}_{3}$, molecular weight - 262, melting point- 225-230 ${ }^{\circ} \mathrm{C}$, elemental analysis \% found (calcd.): C, 53.99 (54.96); H, 5.01(5.38); N, 20.89 (21.36); and O, 17.86 (18.30). 


\section{Medium}

The medium for the study was prepared from reagent grade $\mathrm{HNO}_{3}$ (Assay 69\% $\mathrm{Cl}^{-}, 0.00005 \% ; \mathrm{SO}_{4}, 0.0001 \% ; \mathrm{Pb}, 0.000005 \% ; \mathrm{Cu}, 0.000005 \% ; \mathrm{Ni}, 0.000005 \%$; $\mathrm{Zn}, 0.00001 \%$; Cd, 0.000001\%; Fe, 0.00002\%; Ca, 0.0001\% and As, $0.000001 \%$, E.merk) and double distilled water. All the tests were performed in aerated medium at different temperatures under normal atmospheric pressure.

\section{Materials}

The copper electrode was made from $99.99 \%$ pure copper (confirmed with EDX spectra) in the form of circular coupons. The copper specimen was embedded in a Teflon holder with an exposed area of $1 \mathrm{~cm}^{2}$. Before each experiment, the coupons were polished using different grade emery papers followed by washing with different solvents as recommended by ASTM and finally with distilled water.

\section{Electrochemical measurements}

Electrochemical tests were carried out in a conventional three-electrode polymethylmethacrylate (PMMA, room temperature)/borosilicate glass (high temperature) cell with platinum $\left(1 \mathrm{~cm}^{2}\right.$ surface area) as auxiliary electrode, and saturated calomel electrode (SCE) as the reference electrode. The working electrode was first immersed in the test solution for establishing a steady state open circuit potential (OCP), and then the electrochemical measurements were carried out with a computer controlled Gill AC electrochemical workstation (ACM, U.K, model no: 1475). Electrochemical impedance spectroscopy (EIS) measurements were carried out in the frequency range $10 \mathrm{kHz}$ to $0.1 \mathrm{~Hz}$ with the amplitude of $5 \mathrm{mV}$ (RMS) using a.c signals at open circuit potential. The potentiodynamic polarization studies were performed by sweeping the potential between $-250 \mathrm{mV}$ and $+250 \mathrm{mV}$ at a scan rate of $1000 \mathrm{mV} /$ minutes $(16$ $\mathrm{mV} / \mathrm{sec}$ ). In order to investigate the effects of temperature on the inhibition performance, polarization and impedance studies were carried at various temperatures (303-323 K) in the absence and presence of different concentrations of MBATD (25, 50, 100 and $200 \mathrm{ppm})$. All electrochemical measurements were made after $1 \mathrm{~h}$ immersion in corrosive media in the absence and presence of inhibitors and the reasonable reproducibility is achieved through repetition.

\section{Quantum chemical calculation}

Quantum chemical calculations and geometry optimizations were performed using $a b$ initio calculations and the density functional theory (DFT). Ab initio calculations were carried out using the Hatree-Fock (HF) method. The Becke's three- parameter hybrid functional combined with the Lee, Yang and Parr correlation function (B3LYP) was employed in the DFT calculations using 6$31 \mathrm{G}$ (d) basis set. All the quantum chemical calculations were carried out with complete geometry optimization using Gaussian-03W programme package [1719].

The chemical reactivity of different sites of the molecule was evaluated by Fukui indices, defined by:

For nucleophilic attack: $\quad \int_{\mathrm{k}}^{+}=\mathrm{q}_{\mathrm{N}+1^{-}}-\mathrm{q}_{\mathrm{N}}$

For electrophilic attack: $\quad \int_{\mathrm{k}}{ }^{-}=\mathrm{q}_{\mathrm{N}}-\mathrm{q}_{\mathrm{N}-1}$ 
where $\mathrm{q}_{\mathrm{N}}, \mathrm{q}_{\mathrm{N}-1}$ and $\mathrm{q}_{\mathrm{N}+1}$ are the electronic population of the atom $\mathrm{k}$ in neutral, cationic and anionic systems, respectively [20,21]. The condensed Fukui function is to the local reactivity descriptor and thus can be used only for comparing reactive atomic centers within the same molecule, whereas condensed softness indices allow the comparison of the reactivity between similar atoms of different molecules, condensed softness indices which can be calculated easily starting from the relation between the Fukui function $\int(r)$ and the local softness $\mathrm{S}(\mathrm{r})$.

$\mathrm{S}(\mathrm{r})=\left((\partial \rho(\mathrm{r}) / \partial \mathrm{N})_{\mathrm{v}(\mathrm{r})}(\partial \mathrm{N} / \partial \mu)_{\mathrm{v}(\mathrm{r})}=\int(\mathrm{r}) \mathrm{S}\right.$

As shown by De Profit et al. [22, 23], the B3LYP functional appears to be reliable for calculating $\int(\mathrm{r})$ and $\int_{\mathrm{k}}$ indices. The molecular dynamics simulations were performed to understand the adsorption behavior of MBATD on copper (110) surface using Material Studio 4.3 programme package. The copper substrate with (110) plane was first optimized to minimum energy, and then the addition of the MBATD molecule on the $\mathrm{Cu}$ (110) surface was simulated using the compass force field [24].

\section{Scanning electron microscopy (SEM)}

The surface morphologies of the samples in the absence and presence of the inhibitor were carried out using a digital Scanning Electron Microscope model SU6600 (Serial No: HI-2102-0003) with an accelerating voltage of $20.0 \mathrm{kV}$, at a scan speed Slow5 and calibration scan speed of 25. Samples were attached on the top of an aluminium stopper by means of carbon conductive adhesive tape. All micrographs of the specimen were taken at the magnification of $500 \mathrm{xs}$. These samples underwent the same pre-treatment as used in electrochemical experiments before recording the SEM image.

\section{Results and discussion}

\section{Potentiodynamic polarization studies}

Tafel polarization curves for copper in unstirred $1 \mathrm{M} \mathrm{HNO}_{3}$ solution in the absence and presence of various concentrations of MBATD at 303, 313 and 323 $\mathrm{K}$ are presented in Figs. 2-4. According to corrosion theories [25, 26], the rightward shift of the cathodic curves reveals that the corrosion is mainly accelerated by cathodic reactions. Being a strong oxidizing agent, $\mathrm{HNO}_{3}$ is capable of attacking copper. The Tafel polarization curves exhibit no steep slope in the anodic range, which proves that no passive film is formed on the copper surface. As a result, copper may directly dissolve in $1 \mathrm{M} \mathrm{HNO}_{3}$ solution. Copper is corroded to $\mathrm{Cu}^{2+}$ in $\mathrm{HNO}_{3}$ solutions, and no oxide film is formed to protect the surface from the attack of the corrosive medium. Copper dissolution is thus expected to be the dominant reaction in $\mathrm{HNO}_{3}$ solution. The electrochemical reactions for copper in $1 \mathrm{M} \mathrm{HNO}_{3}$ solution may be described as follows: 
Anodic reaction

$\mathrm{Cu} \rightarrow \mathrm{Cu}^{2+}+2 \mathrm{e}^{-}$

Cathodic reactions:

$\mathrm{NO}_{3}^{-}+3 \mathrm{H}^{+}+2 \mathrm{e}^{-} \rightarrow \mathrm{HNO}_{2}+\mathrm{H}_{2} \mathrm{O}$

$\mathrm{NO}_{3}^{-}+4 \mathrm{H}^{+}+3 \mathrm{e}^{-} \rightarrow \mathrm{NO}+2 \mathrm{H}_{2} \mathrm{O}$

$\mathrm{O}_{2}+4 \mathrm{H}^{+}+4 \mathrm{e}^{-} \rightarrow 2 \mathrm{H}_{2} \mathrm{O}$

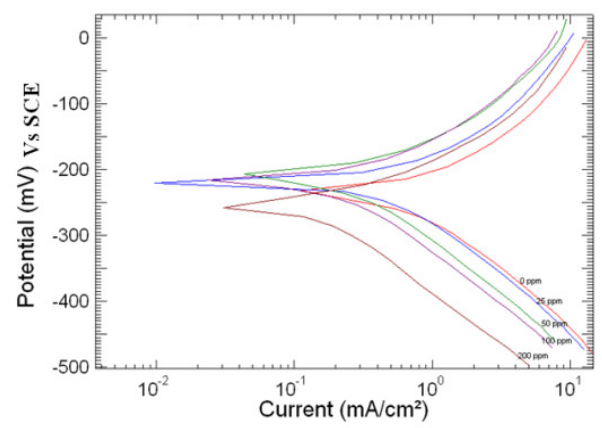

Figure 2. Polarization curve of copper in $1 \mathrm{M} \mathrm{HNO}_{3}$ in the absence and presence of different concentrations of MBATD at $303 \mathrm{~K}$.

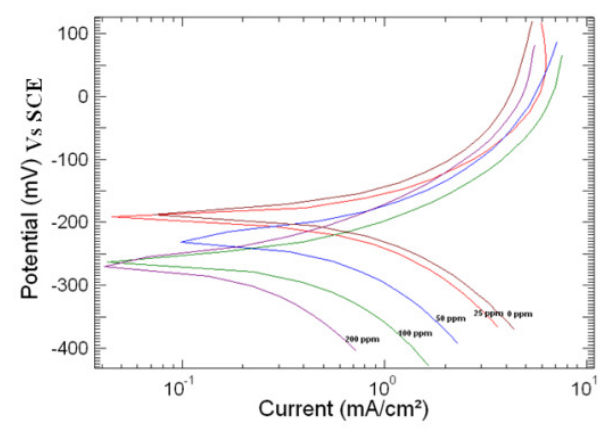

Figure 3. Polarization curve of copper in $1 \mathrm{M} \mathrm{HNO}_{3}$ in the absence and presence of different concentrations of MBATD at $313 \mathrm{~K}$.

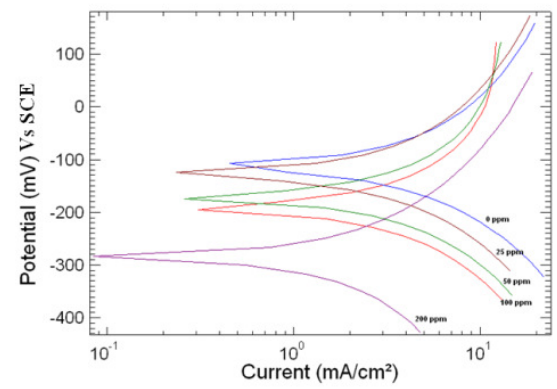

Figure 4. Polarization curve of copper in $1 \mathrm{M} \mathrm{HNO}_{3}$ in the absence and presence of different concentrations of MBATD at $323 \mathrm{~K}$.

Electrochemical potentiokinetic parameters like corrosion potential $\left(\mathrm{E}_{\mathrm{corr}}\right)$, cathodic and anodic Tafel slopes $\left(\beta_{\mathrm{c}}\right.$ and $\beta_{\mathrm{a}}$ ), and corrosion current density ( $\left.\mathrm{i}_{\text {corr }}\right)$ obtained from Tafel extrapolation of the polarization curve at 303, 313 and 323 $\mathrm{K}$ are given in Table 1 . The corrosion inhibition efficiency was calculated using the relation: 


$$
\% \mathrm{IE}=1-\frac{\mathrm{i}_{\text {corr }}}{\mathrm{i}_{\text {corr }}^{\mathbf{o}}} \times 100
$$

where $i_{\text {corr }}^{0}$ and $i_{\text {corr }}$ are uninhibited and inhibited corrosion current density, respectively. It is evident from Figs. 2-4 that the inhibitor molecule reduces both the anodic and cathodic current densities during its inhibitory action. The Tafel slope values given in Table 1 also support this observation. The change in the slopes of the cathodic Tafel lines $\left(\beta_{\mathrm{c}}\right)$ and anodic Tafel lines $\left(\beta_{\mathrm{a}}\right)$ observed with the addition of the inhibitor molecule is a clear evidence of the action of the inhibitor molecule on cathodic and anodic reactions. These changes in the values of the anodic and cathodic Tafel slopes $\left(\beta_{\mathrm{a}} \& \beta_{\mathrm{c}}\right)$ suggest that MBATD acts as a mixed type inhibitor. The linear polarization resistance (LPR) obtained from linear polarization curves (another form of Tafel plots, graphs not given) is also shown in Table 1, and it means good inhibition efficiency for MBATD. The presence of defects on the metal surface permits free access to $\mathrm{H}^{+}$ions and encourages the dissolution process of the metal $[27,28]$. The surface coverage increases with the inhibitor concentration. This film reduces the active surface area available to the corrosive medium and delays the gas evolution and copper dissolution [29].

Table 1. Electrochemical parameters for copper obtained from polarization curves in 1 $\mathrm{M} \mathrm{HNO}_{3}$ at 303,313 and $323 \mathrm{~K}$.

\begin{tabular}{llllccccc}
\hline $\begin{array}{l}\text { Temp. } \\
(\mathrm{K})\end{array}$ & $\begin{array}{c}\text { Conc. } \\
(\mathrm{ppm})\end{array}$ & $\begin{array}{l}\mathrm{E}_{\text {corr }} \\
(\mathrm{mV} / \mathrm{SCE})\end{array}$ & $\begin{array}{l}\text { L.P.R } \\
\left(\Omega \mathrm{cm}^{2}\right)\end{array}$ & $\begin{array}{c}\beta_{\mathrm{a}} \\
\left(\mathrm{mV} \mathrm{dec}^{-1}\right)\end{array}$ & $\begin{array}{c}\beta_{\mathrm{c}} \\
\left(\mathrm{mV} \mathrm{dec}^{-1}\right)\end{array}$ & $\begin{array}{c}\mathrm{i}_{\text {corr }} \\
\left(\mu \mathrm{A} \mathrm{cm} \mathrm{cm}^{-2}\right)\end{array}$ & $\begin{array}{c}\text { C.R } \\
(\mathrm{mm} / \mathrm{yr})\end{array}$ & $\begin{array}{c}\text { I.E } \\
(\%)\end{array}$ \\
\hline \multirow{6}{*}{303} & Blank & -232 & 23 & 116 & 176 & 1308 & 14.72 & --- \\
& 25 & -219 & 29 & 118 & 170 & 833 & 10.72 & 37 \\
& 50 & -206 & 37 & 91 & 163 & 481 & 5.35 & 63 \\
& 100 & -246 & 39 & 93 & 154 & 312 & 4.62 & 76 \\
& 200 & -256 & 47 & 96 & 159 & 199 & 3.27 & 85 \\
& & & & & & & & \\
313 & Blank & -164 & 11 & 115 & 190 & 2623 & 39.12 & --- \\
& 25 & -208 & 17 & 184 & 188 & 1741 & 27.43 & 34 \\
& 50 & -210 & 29 & 77 & 155 & 949 & 10.01 & 64 \\
& 100 & -202 & 38 & 101 & 150 & 690 & 8.67 & 74 \\
& 200 & -225 & 45 & 67 & 143 & 417 & 6.92 & 84 \\
& & & & & & & & \\
323 & 25 & -130 & 12 & 111 & 102 & 1841 & 41.12 & 32 \\
& 50 & -187 & 13 & 78 & 104 & 1092 & 25.56 & 60 \\
& 100 & -147 & 18 & 41 & 36 & 712 & 18.14 & 73 \\
& 200 & -128 & 19 & 41 & 45 & 543 & 12.81 & 80 \\
\hline
\end{tabular}

\section{Electrochemical impedance spectroscopy}

In order to understand the adsorption and inhibition mechanism of MBATD on copper surface, electrochemical impedance spectroscopy measurements were performed to the copper/electrolyte solution interface. The Nyquist plots and the representative Bode diagrams for the uninhibited $1 \mathrm{M} \mathrm{HNO}_{3}$ and solution containing different inhibitor concentrations at various temperatures are given in Figs. 5-10. 
The Nyquist plots display a capacitive loop at high frequencies (may be due to charge transfer of the corrosion process) and a straight line at low frequencies (may be due to diffusion of soluble reactant or product species). It is evident from Figs. 5-7 that the impedance loops measured are depressed semi-circles with their centers below the real axis. This "dispersing effect" is mainly due to the roughness and other inhomogeneities of the electrode surface [30-34]. So, one constant phase element (Q) is substituted for the capacitive element in the equation to get a more accurate fit.

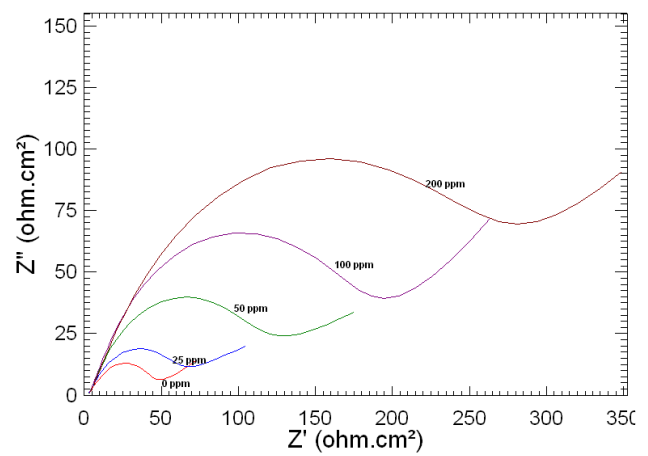

Figure 5. Nyquist plots of copper in $1 \mathrm{M} \mathrm{HNO}_{3}$ in the absence and presence of different concentrations of MBATD at $303 \mathrm{~K}$.

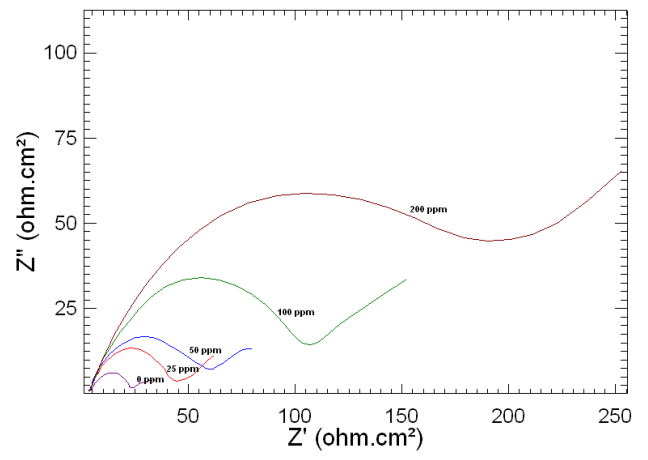

Figure 6. Nyquist plots of copper in $1 \mathrm{M} \mathrm{HNO}_{3}$ in the absence and presence of different concentrations of MBATD at $313 \mathrm{~K}$.

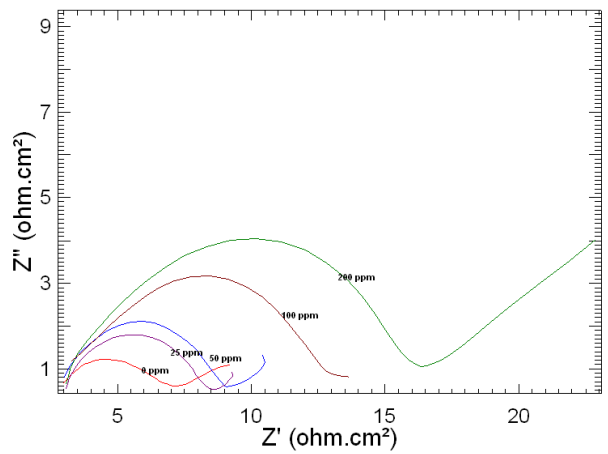

Figure 7. Nyquist plots of copper in $1 \mathrm{M} \mathrm{HNO}_{3}$ in the absence and presence of different concentrations of MBATD at $323 \mathrm{~K}$. 


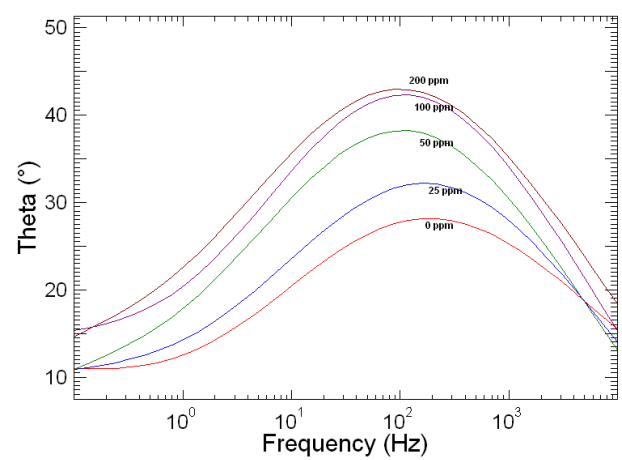

Figure 8. Bode plots of copper in $1 \mathrm{M} \mathrm{HNO}_{3}$ in the absence and presence of different concentrations of MBATD at $303 \mathrm{~K}$.

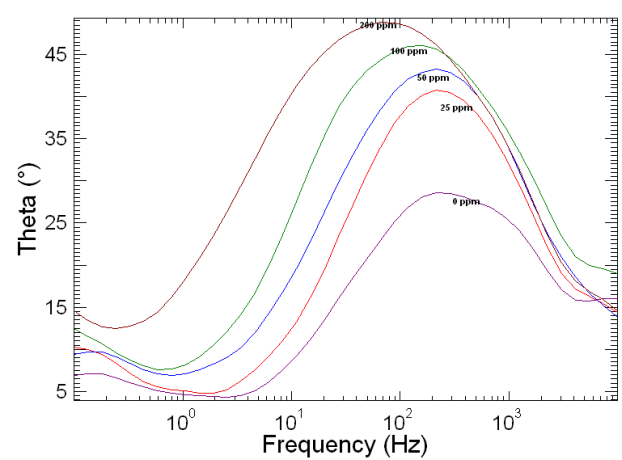

Figure 9. Bode plots of copper in $1 \mathrm{M} \mathrm{HNO}_{3}$ in the absence and presence of different concentrations of MBATD at $313 \mathrm{~K}$.

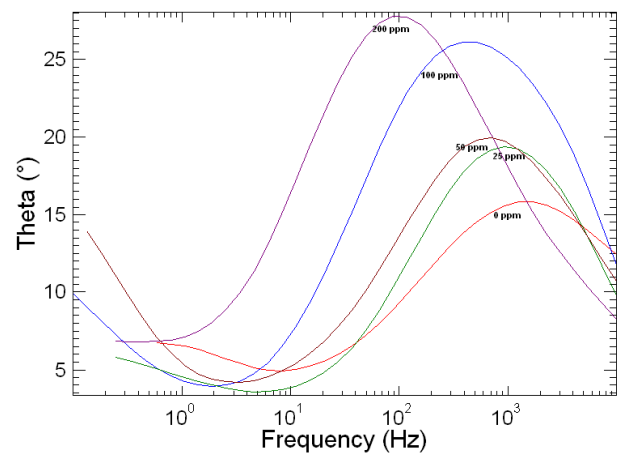

Figure 10. Bode plots of copper in $1 \mathrm{M} \mathrm{HNO}_{3}$ in the absence and presence of different concentrations of MBATD at $323 \mathrm{~K}$.

The impedance of a constant phase element is described by the expression:

$$
\mathrm{Z}_{\mathrm{Q}}=Y_{0}^{-1}(j \omega)^{-n}
$$

where $\mathrm{Y}_{0}$ is a proportional factor, $\mathrm{n}$ has the meaning of a phase shift. For $\mathrm{n}=0, \mathrm{Q}$ represents a resistance, for $\mathrm{n}=1$, a capacitance, for $\mathrm{n}=0.5$, a Warburg element and for $\mathrm{n}=-1$ an inductance. According to Hsu and Mansfeld [35], the values of the double layer capacitance $\left(\mathrm{C}_{\mathrm{dl}}\right)$ can be obtained from the equation:

$$
\mathrm{C}_{\mathrm{dl}}=\operatorname{Yo}\left(\omega_{\mathrm{m}}^{\prime \prime}\right)^{\mathrm{n}-1}
$$


where $\omega_{\mathrm{m}}^{\prime \prime}$ is the frequency at which the imaginary part of the impedance has a maximum.

Charge transfer resistance $\left(\mathrm{R}_{\mathrm{ct}}\right)$ and double layer capacitance $\left(\mathrm{C}_{\mathrm{dl}}\right)$ are given in Table 2.

Table 2. AC impedance data of copper with MBATD in $1 \mathrm{M} \mathrm{HNO}_{3}$ solutions at 303, 313 and $323 \mathrm{~K}$.

\begin{tabular}{llrrrrr}
\hline $\begin{array}{l}\text { Temp. } \\
(\mathrm{K})\end{array}$ & $\begin{array}{c}\text { Conc. } \\
(\mathrm{ppm})\end{array}$ & $\begin{array}{c}\mathrm{R}_{\mathrm{ct}} \\
\left(\Omega \mathrm{cm}^{2}\right)\end{array}$ & $\begin{array}{c}\mathrm{C}_{\mathrm{dl}} \\
\left(\mu \mathrm{F} \mathrm{cm}^{-2}\right)\end{array}$ & $\begin{array}{c}\mathrm{i}_{\text {corr }} \\
\left(\mu \mathrm{A} \mathrm{cm}^{-2}\right)\end{array}$ & $\begin{array}{c}\mathrm{C} . \mathrm{R} \\
(\mathrm{mm} / \mathrm{yr})\end{array}$ & $\begin{array}{c}\text { I.E } \\
(\%)\end{array}$ \\
\hline \multirow{3}{*}{303} & Blank & 45 & 8.08 & 576 & 13.41 & --- \\
& 25 & 70 & 7.27 & 370 & 8.62 & 36 \\
& 50 & 130 & 4.38 & 201 & 4.64 & 65 \\
& 100 & 200 & 2.79 & 130 & 3.02 & 76 \\
& 200 & 311 & 2.66 & 83 & 1.95 & 86 \\
& & & & & & \\
313 & Blank & 14 & 6.35 & 1784 & 40.05 & -- \\
& 25 & 21 & 5.41 & 1180 & 29.69 & 33 \\
& 50 & 37 & 4.47 & 660 & 11.41 & 62 \\
& 100 & 58 & 4.14 & 436 & 9.67 & 75 \\
& 200 & 91 & 1.32 & 269 & 7.50 & 84 \\
& & & & & & \\
& Blank & 6 & 5.01 & 3894 & 94.58 & --- \\
& 25 & 9 & 4.74 & 2668 & 65.33 & 33 \\
& 50 & 15 & 3.79 & 1574 & 37.39 & 60 \\
& 100 & 23 & 2.52 & 995 & 25.51 & 74 \\
& 200 & 31 & 1.14 & 753 & 19.83 & 80 \\
\hline
\end{tabular}

It is observed that the values of the polarization resistance increase with the inhibitor concentration. In the case of impedance studies, \%IE is calculated with the equation:

$$
\% \mathrm{IE}=1-\frac{\mathrm{R}_{\mathrm{ct}}^{\mathrm{o}}}{\mathrm{R}_{\mathrm{ct}}}
$$

where $\mathrm{R}_{\mathrm{ct}}^{\circ}$ and $\mathrm{R}_{\mathrm{ct}}$ are the values of the charge transfer resistance observed in the absence and presence of MBATD. The inhibition efficiencies calculated from EIS studies show the same trend of polarization measurements. The small difference in the inhibition efficiency of these two methods may be attributed to the different surface status of the electrode in these two measurements. EIS measurements were performed at the rest potential, while in polarization measurements the electrode surface was polarized due to high over potential, non-uniform current distributions resulted from cell geometry, solution conductivity, counter and reference electrode placement, etc., and will lead to the difference between the electrode area actually undergoing polarization and the total area [36]. As it can be seen from Table 2, the $C_{\mathrm{dl}}$ values tend to decrease with the increase of the inhibitor concentration. The decrease in the $C_{d l}$, which can result from a decrease in local dielectric constant and/or an increase in the 
thickness of the electrical double layer, suggests that MBATD molecule functions by adsorption at the metal/solution interface [37].

\section{Adsorption isotherm and thermodynamic parameters}

The first step in the inhibition of metallic corrosion is the adsorption of the organic molecule at the metal/solution interface. It depends on the molecule's chemical composition, the temperature, and the electrochemical potential at the metal/solution interface. In fact, the solvent $\mathrm{H}_{2} \mathrm{O}$ molecules could also adsorb at the metal/solution interface. Thus the adsorption of inhibitor molecule from the aqueous solution can be considered as a quasi-substitution process between the organic compounds in the aqueous phase $\left[\mathrm{Org}_{(\mathrm{sol})}\right]$ and water molecules at the electrode surface $\left[\mathrm{H}_{2} \mathrm{O}_{(\mathrm{ads})}\right]$ [38].

$\operatorname{Org}_{(\text {sol })}+\mathrm{x} \mathrm{H}_{2} \mathrm{O}_{(\text {ads }) \leftrightarrow} \operatorname{Org}_{(\mathrm{ads})}+\mathrm{x} \mathrm{H}_{2} \mathrm{O}_{(\mathrm{sol})}$

where $\mathrm{x}$ is the size ratio (number of water molecules replaced by one molecule of the organic inhibitor).

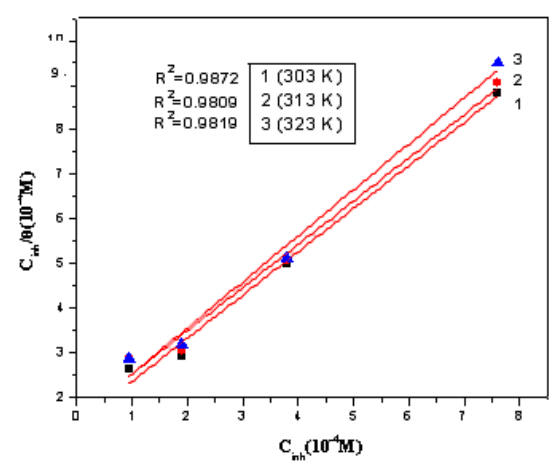

Figure 11. Langmuir adsorption isotherm for MBATD on copper surface in $1 \mathrm{M} \mathrm{HNO}_{3}$ : 1) at $303 \mathrm{~K}$; 2) at $313 \mathrm{~K}$ and 3 ) at $323 \mathrm{~K}$.

Basic information on the interaction between the inhibitor molecule and the copper surface can be obtained from the adsorption isotherm. In order to obtain the isotherm, linear relation between surface coverage $(\theta)$ values $(\theta=\%$ IE /100; Table 2) and inhibitor concentration $\left(\mathrm{C}_{\mathrm{inh}}\right)$ must be found. From attempts to fit the $\theta$ values to different isotherms, the best-fit result is obtained with the Langmuir isotherm.

$$
\frac{\mathrm{C}_{\mathrm{inh}}}{\theta}=\frac{1}{\mathrm{~K}_{\mathrm{ads}}}+\mathrm{C}_{\mathrm{inh}}
$$

where $\mathrm{K}_{\mathrm{ads}}$ is the equilibrium constant of the adsorption process. The plot of $\left(\mathrm{C}_{\mathrm{inh}} / \theta\right)$ versus $\mathrm{C}_{\mathrm{inh}}$ gave a straight line at various temperatures (Fig.11). The values of the linear regression coefficients $\left(\mathrm{R}^{2}\right)$ confirm that the adsorption of MBATD follows Langmuir adsorption isotherm. The free energy of adsorption $\left(\Delta \mathrm{G}_{\mathrm{ads}}^{\mathrm{o}}\right.$ ) is related to the adsorption constant $\left(\mathrm{K}_{\mathrm{ads}}\right)$ with the following equation [39]. 


$$
\mathrm{K}_{\mathrm{ads}}=\frac{1}{55.5} \exp \left(\frac{-\Delta \mathrm{G}_{\mathrm{ads}}^{\mathrm{o}}}{\mathrm{RT}}\right)
$$

where $\mathrm{R}$ is the universal gas constant, $\mathrm{T}$ is the thermodynamic temperature and 55.5 is the concentration of water in the solution expressed in $\mathrm{mol}^{-1}$. The values of free energy of adsorption and adsorption constant are listed in Table 3. The negative values of $\Delta \mathrm{G}_{\mathrm{ads}}^{\mathrm{o}}$ and the higher values of $\mathrm{K}_{\mathrm{ads}}\left(\geq 100 \mathrm{M}^{-1}\right)$ ensure the spontaneity of the adsorption process and are characteristic of strong interaction and stability of the adsorbed layer [40]. However, the value of entropy of adsorption is positive. In fact, it is well known that adsorption is an exothermic phenomenon accompanied by a decrease in entropy. In aqueous solution, the adsorption of organic molecule is generally accompanied with desorption of water molecules. The adsorption of an organic adsorbate at the metal/solution interface is considered as "substitutional adsorption" phenomenon. Therefore, the

Table 3. Thermodynamic parameters for the adsorption of MBATD in $1 \mathrm{M} \mathrm{HNO}_{3}$ on copper in the presence of $200 \mathrm{ppm}$ at different temperatures.

\begin{tabular}{|c|c|c|c|c|}
\hline $\begin{array}{c}\text { Temperature } \\
(\mathrm{K})\end{array}$ & $\begin{array}{c}\mathrm{K}_{\text {ads }} \\
\left(\mathrm{M}^{-1}\right)\end{array}$ & $\begin{array}{c}\Delta \mathrm{G}_{\text {ads }}^{0} \\
\left(\mathrm{kJmol}^{-1}\right)\end{array}$ & $\begin{array}{c}\Delta \mathrm{H}_{\text {ads }}^{0} \\
\left(\mathrm{kJmol}^{-1}\right)\end{array}$ & $\begin{array}{c}\Delta \mathrm{S}_{\text {ads }}^{0} \\
\left(\mathrm{Jmol}^{-1} \mathrm{~K}^{-1}\right)\end{array}$ \\
\hline 303 & 8080 & -32.79 & -16.88 & 52.67 \\
313 & 6909 & -33.46 & & \\
323 & 5264 & -33.80 & & \\
\hline
\end{tabular}

positive values of $\Delta \mathrm{H}_{\text {ads }}^{0}$ and $\Delta \mathrm{S}_{\text {ads }}^{0}$ relate to "substitutional adsorption". It is generally accepted that the values of $\Delta \mathrm{G}_{\text {ads }}^{\mathrm{o}}$ up to $-20 \mathrm{~kJ} / \mathrm{mol}$ are consistent with electrostatic interaction between the charged molecules and the charged metal (physisorption), and the values around $-40 \mathrm{~kJ} / \mathrm{mol}$ or higher are associated with chemisorption, because of sharing or transfer of electrons from organic molecules to the metal surface to form a coordinate type of bond [41]. The value of calculated $\Delta \mathrm{G}_{\mathrm{ads}}^{\mathrm{o}}$ corresponding to MBATD lies between $-32 \mathrm{kjmol}^{-1}$ and -33 $\mathrm{kjmol}^{-1}$. This indicates that the adsorption is not a simple physical adsorption but it may involve some other interactions also. The thermodynamic parameters are also important for studying the mechanism of corrosion inhibition. The heat of adsorption $\left(\Delta \mathrm{H}_{\mathrm{ads}}^{0}\right)$ is calculated using the Van't Hoff equation [42]

$$
\ln \mathrm{K}_{\mathrm{ads}}=\frac{-\Delta \mathrm{H}_{\mathrm{ads}}^{0}}{\mathrm{RT}}+\text { constant }
$$

To calculate the heat of adsorption, $\ln \mathrm{K}_{\mathrm{ads}}$ and $1 / \mathrm{T}$ were plotted and are given in Fig. 12. From the straight line graph the slope $\left(-\Delta \mathrm{H}_{\mathrm{ads}}^{0} / \mathrm{R}\right)$ and intercept $\left(\Delta \mathrm{S}_{\text {ads }}^{0} / \mathrm{R}+\ln (1 / 55.5)\right)$ values are calculated. The calculated values of heat of adsorption and entropy of adsorption are given in Table 3 .The negative sign of 
$\Delta \mathrm{H}_{\text {ads }}^{0}$ indicates that the adsorption of the inhibitor molecule is an exothermic process. The value of $\Delta S_{\text {ads }}^{0}$ in the presence of the inhibitor is positive meaning that an increase in disordering takes place on going from reactants to the metal adsorbed reaction species [43].

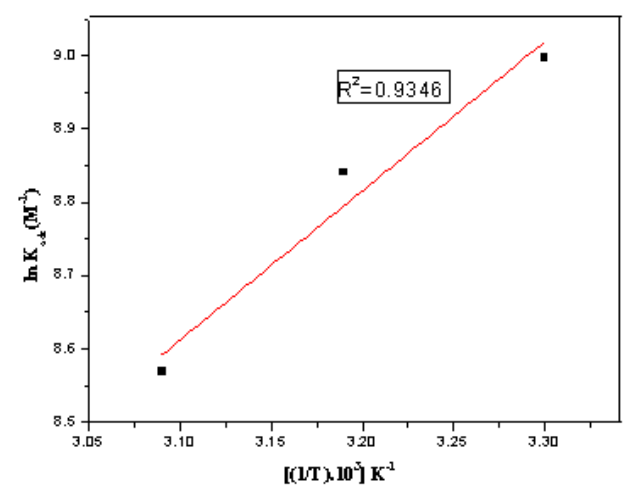

Figure 12. Adsorption isotherm plot for $\ln k_{a d s}$ vs. 1/T of MBATD on mild steel in1 $M$ $\mathrm{HCl}$.

\section{Effect of temperature and kinetic parameters}

The effect of temperature on various corrosion parameters like $\mathrm{E}_{\text {corr }}, \mathrm{i}_{\text {corr }}$ and \% IE were studied in $1 \mathrm{M} \mathrm{HNO}_{3}$ at three different temperatures, 303, 313 and 323 $\mathrm{K}$, in the absence and presence of different inhibitor concentrations. Variation of temperature has almost no effect on the general shape of the polarization and impedance graphs. The results are listed in Tables 1 and 2. Inspection of these tables shows that, as the temperature increases, the values of $i_{\text {corr }}$ increase, and inhibition efficiency and surface coverage decrease. This proves that the inhibition occurs through the adsorption of MBATD on copper surface. The inhibition properties of MBATD can also be explained by kinetic model. The activation parameters were calculated from Arrhenius equation and transition state equations $[44,45]$ :

$$
\begin{aligned}
\mathrm{i}_{\text {corr }} & =\mathrm{k} \exp \left(-\frac{\mathrm{E}_{\mathrm{a}}}{\mathrm{RT}}\right) \\
\mathrm{i}_{\text {corr }} & =\frac{\mathrm{RT}}{\mathrm{Nh}} \exp \left(\frac{\Delta \mathrm{S}_{\mathrm{a}}^{\mathbf{o}}}{\mathrm{R}}\right) \exp \left(-\frac{\Delta \mathrm{H}_{\mathrm{a}}^{\mathrm{o}}}{\mathrm{RT}}\right)
\end{aligned}
$$

where $E_{a}$ is the activation energy, $k$ is the Arrhenius pre-exponential factor, $T$ is the absolute temperature, $\mathrm{R}$ is the gas constant, $\mathrm{h}$ is Planck's constant, $\mathrm{N}$ is Avogadro's number, $\Delta \mathrm{S}_{\mathrm{a}}^{\mathbf{0}}$ is the entropy of activation, and $\Delta H_{a}^{0}$ is the enthalpy of activation.

Table 4. Activation parameters for copper in $1 \mathrm{M} \mathrm{HNO}_{3}$ in absence and presence of MBATD.

\begin{tabular}{|l|c|c|c|}
\hline $\begin{array}{l}\text { Conc. } \\
(\mathrm{ppm})\end{array}$ & $\begin{array}{c}\mathrm{E}_{\mathrm{a}} \\
\left(\mathrm{kJmol}^{-1}\right)\end{array}$ & $\begin{array}{c}\Delta \mathrm{H}_{\mathrm{a}}^{0} \\
\left(\mathrm{kJmol}^{-1}\right)\end{array}$ & $\begin{array}{c}\Delta \mathrm{S}_{\mathrm{a}}^{\mathbf{o}} \\
\left(\mathrm{Jmol}^{-1} \mathrm{~K}^{-1}\right)\end{array}$ \\
\hline $\begin{array}{l}\text { Blank } \\
200\end{array}$ & 29.3792 & 26.85 & -95.96 \\
\end{tabular}




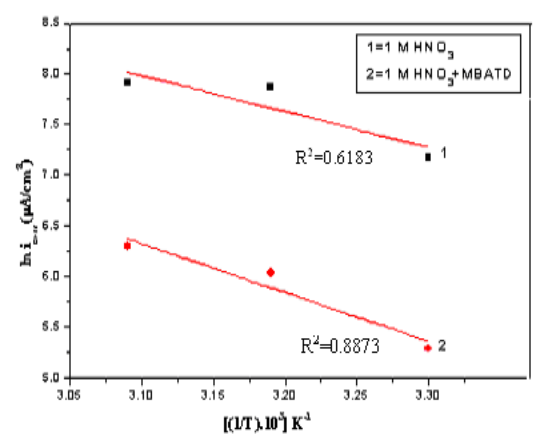

Figure 13. Arrhenius plots of $\ln \left(\mathrm{i}_{\text {corr }}\right)$ versus $1 / \mathrm{T}$ : (1) $1 \mathrm{M} \mathrm{HCl}$, (2) $1 \mathrm{M} \mathrm{HCl}+\mathrm{MBATD}$.

A plot of $\ln \mathrm{i}_{\text {corr }}$ versus $1 / \mathrm{T}$ gave a straight line, as shown in Fig. 13. The values of activation energy obtained from the slope of the lines are listed in Table 4. The increase of $E_{a}$ value with MBATD may be due to either physical adsorption that occurs in the first stage or to the decrease in the adsorption of the inhibitor molecule on the metal surface with increase of temperature [46-49].

To obtain the values of enthalpy and entropy of activation processes, a plot of $1 n$ $\left(\mathrm{i}_{\text {corr }} / \mathrm{T}\right)$ against $1 / \mathrm{T}$ is constructed and given in Figure 14. Straight lines were obtained with a slope of $(-\Delta \mathrm{H} / \mathrm{R})$ and an intercept of $[\ln (\mathrm{R} / \mathrm{Nh})+(\Delta \mathrm{S} / \mathrm{R})]$ and the calculated values of $\Delta \mathrm{H}$ and $\Delta \mathrm{S}$ are given in Table 4 . The positive signs of the enthalpies $(\Delta \mathrm{H})$ reflect the endothermic nature of the metal dissolution process suggesting that the dissolution of copper is slow in the presence of the inhibitor [50].

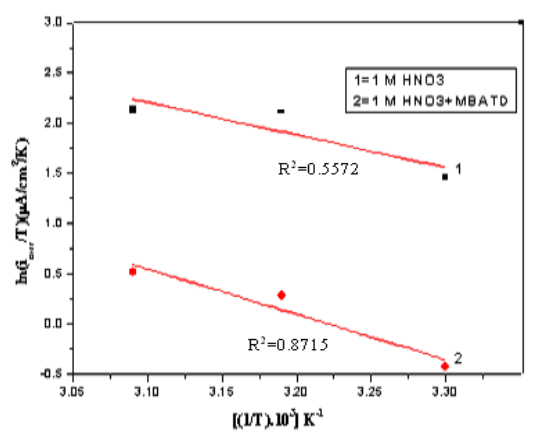

Figure 14. Arrhenius plots of $\ln \left(\mathrm{i}_{\text {corr }} / \mathrm{T}\right)$ versus $1 / \mathrm{T}$ : (1) $1 \mathrm{M} \mathrm{HCl}$, (2) $1 \mathrm{M} \mathrm{HCl}+$ MBATD.

\section{Quantum chemical calculations}

Quantum chemical calculations are performed to understand the effect of structural parameters on inhibition efficiency of MBATD and to study its adsorption mechanism on copper surface. The optimized structure of MBATD in its ground state is given in Fig.15 (a).

Frontier orbital theory is useful in predicting the adsorption centers of the inhibitor molecule responsible for the interaction with surface metal atoms. It is reported that excellent corrosion inhibitors are usually those organic compounds 
which are not only offering electrons to unoccupied molecular orbital of the metal, but also accept free electrons from the metal. From the literature it is clear that the higher the HOMO energy of the inhibitor, the greater the trend of offering electrons to the unoccupied 'd' orbital of the metal, and higher will be the corrosion inhibition efficiency. The lower the LUMO energy, the easier the acceptance of electrons by the $\pi$ orbitals of MBATD from the metal. The decrease in the LUMO-HOMO energy gap increases the efficiency of the inhibitor. The pictorial representations of the HOMO and LUMO of MBATD are given in Fig.15 (b) and (c). Quantum chemical parameters listed in Table 5 reveal that MBATD has high HOMO and low LUMO with low-energy gap and thus possesses higher inhibition efficiency.

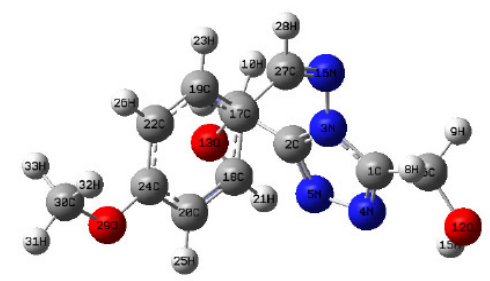

(a)

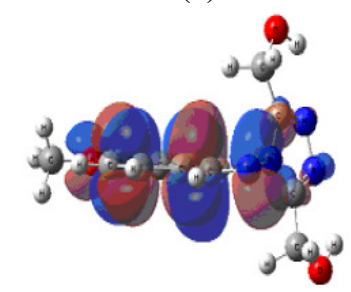

(c)

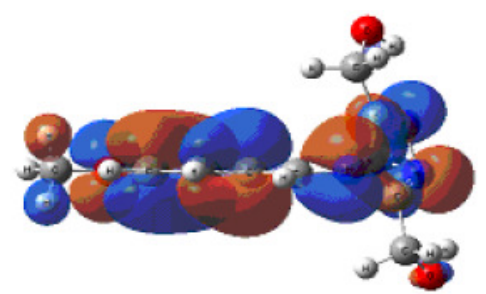

(b)

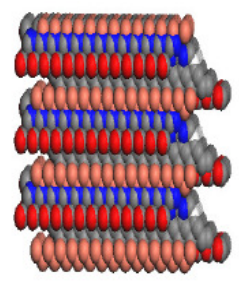

(d)

Figure 15. (a) Optimized geometry of the inhibitor molecule, (b) highest occupied molecular orbital (HOMO) of the inhibitor, (c) lowest unoccupied molecular orbital (LUMO) of the inhibitor, and (d) mode of adsorption of the inhibitor molecule on copper (110) plane.

Table 5. Various quantum chemical parameters calculated by computational/simulation studies.

\begin{tabular}{llll}
\hline Adsorption parameters & \multicolumn{2}{c}{ Quantum chemical parameters } \\
\hline Total energy $\left(\mathrm{kcal} \mathrm{mol}^{-1}\right)$ & -121.1174 & Total energy $\left(\mathrm{kcal} \mathrm{mol}^{-1}\right)$ & 571034.10 \\
Adsorption energy $\left(\mathrm{kcal} \mathrm{mol}^{-1}\right)$ & -9.6631 & $\mathrm{E}_{(\mathrm{HOMO})}(\mathrm{eV})$ & -2.1056 \\
Rigid adsorption energy $\left(\mathrm{kcal} \mathrm{mol}^{-1}\right)$ & -9.4796 & $\mathrm{E}_{(\mathrm{LUMO})}(\mathrm{eV})$ & -6.7365 \\
Deformation energy $\left(\mathrm{kcal} \mathrm{mol}^{-1}\right)$ & -19.1423 & $\Delta \mathrm{E}(\mathrm{eV})$ & 4.6309 \\
$\mathrm{dE}_{\mathrm{ad}} / \mathrm{dN}_{\mathrm{i}}\left(\mathrm{kcal} \mathrm{mol}^{-1}\right)$ & -9.6631 & Dipole moment (D) & 8.8682 \\
\hline
\end{tabular}

The number of electrons transferred $(\Delta \mathrm{N})$ was also calculated using the quantum chemical method by the following equation:

$$
\Delta \mathrm{N}=\frac{\chi_{\mathrm{Cu}}-\chi_{\text {inh }}}{2\left(\eta_{\mathrm{Cu}}-\eta_{\mathrm{inh}}\right)}
$$

where $\chi_{\mathrm{Cu}}$ and $\chi_{\text {inh }}$ denote the absolute electro negativity of copper and the inhibitor molecule, and $\eta_{\mathrm{Cu}}$ and $\eta_{\text {inh }}$ denote the absolute hardness of copper and 
inhibitor molecule respectively. These are related to electron affinity (A) and ionization potential (I).

$$
\begin{aligned}
& \chi=(\mathrm{I}+\mathrm{A}) / 2, \eta=(\mathrm{I}-\mathrm{A}) / 2, \text { where } \mathrm{A} \text { and } \mathrm{I} \text { related to } \mathrm{E}_{\mathrm{HOMO}} \text { and } \mathrm{E}_{\mathrm{LUMO}} \\
& \mathrm{I}=-\mathrm{E}_{\mathrm{HOMO}} \\
& \mathrm{A}=-\mathrm{E}_{\mathrm{LUMO}}
\end{aligned}
$$

Using a theoretical $\chi$ value of $4.48 \mathrm{eV} / \mathrm{mol}$ according to Pearson's electro negativity scale, and $\eta$ value of $0 \mathrm{eV} / \mathrm{mol}$ for copper, $\Delta \mathrm{N}$ was calculated. Values of $\Delta \mathrm{N}$ show that inhibition effect resulted from electron donation (Table 6). From Lukovits' study, one can derive the conclusion that if $\Delta \mathrm{N}<3.6$, the inhibition efficiency increases with increasing electron-donating ability at the metal surface. Here, MBATD was the donor of electrons, and the copper oxide surface was the acceptor. MBATD was bound to the copper oxide surface, and thus forming inhibitive adsorption layer against corrosion [51-56].

Table 6. Quantum chemical descriptors for MBATD.

\begin{tabular}{|c|c|c|c|c|c|c|}
\hline Molecule & $\mu$ & $\mathrm{I}$ & $\mathrm{A}$ & $-\chi$ & $\eta$ & $\Delta \mathrm{N}$ \\
\hline MBATD & 8.8682 & 2.1056 & 6.7365 & 2.3155 & 4.4211 & 0.7685 \\
\hline
\end{tabular}

\section{Fukui function and chemical reactivity}

Fukui indices are used for predicting the preferential site of electrophilic attack at MBATD. They are widely used as descriptors of site selectivity for the soft-soft reactions. According to $\mathrm{Li}$ and Evans, the favorite reactive site is that which possesses high value of Fukui indices. For nucleophilic attack the most reactive site of MBATD is the $\mathrm{C}(17)$ atom, and for electrophilic attack the most reactive site is the $N$ (16) atom. These results are given in Table 7.The condensed local softness indices $\mathrm{Sk}^{-}$and $\mathrm{Sk}^{+}$are related to the condensed Fukui functions. The local softness follows the same trend of Fukui functions [57-59].

\section{Molecular dynamics simulations}

Molecular dynamics simulation studies were performed for understanding the nature of interaction between MBATD and copper surface. Structure of MBATD shows that the molecule is likely to adsorb on the metal surface by sharing electron of nitrogen atom, phenyl ring and triazole structure. The periodic boundary conditions were applied to the simulation cell and the whole system was energy optimized, and the possibility of the MBATD adsorption on the copper surface was simulated as in Fig. 15(d). The adsorption energy, the sum of the rigid adsorption energy and deformation energy for the adsorbate components have been calculated. The rigid adsorption energy reports the energy released in $\mathrm{kcal} / \mathrm{mol}$, when the unrelaxed adsorbate components adsorbed on the substrate. The deformation energy reports the energy released when the adsorbed adsorbate components are relaxed on the substrate surface. The total energy, rigid adsorption energy, deformation energy and $\mathrm{dE}_{\mathrm{ad}} / \mathrm{dN}_{\mathrm{i}}$ were calculated by the Monte Carlo simulation [10, 60, and 61] for the adsorption of MBATD molecule on $\mathrm{Cu}$ (110) plane and are presented in Table 5. These findings also confirm the adsorption of MBATD on copper surface. 
Table 7. Fukui functions and local softness values for MBATD.

\begin{tabular}{|lrccc|}
\hline Atom & $\mathrm{f}-$ & $\mathrm{f}+$ & $\mathrm{Sk}^{-}$ & $\mathrm{Sk}^{+}$ \\
\hline $1 \mathrm{C}$ & 0.0109 & 0.0076 & 0.0230 & 0.0160 \\
$2 \mathrm{C}$ & 0.0169 & 0.0078 & 0.0357 & 0.0165 \\
$3 \mathrm{~N}$ & 0.0173 & 0.0045 & 0.0365 & 0.0095 \\
$4 \mathrm{~N}$ & 0.0693 & 0.0035 & 0.1463 & 0.0074 \\
$5 \mathrm{~N}$ & 0.0505 & 0.0028 & 0.1065 & 0.0059 \\
$6 \mathrm{C}$ & 0.0004 & 0.0015 & 0.0008 & 0.0032 \\
$7 \mathrm{C}$ & 0.0004 & 0.0004 & 0.0008 & 0.0008 \\
$8 \mathrm{H}$ & 0.0001 & 0.0001 & 0.0002 & 0.0002 \\
$9 \mathrm{H}$ & 0.0000 & 0.0003 & 0.0000 & 0.0006 \\
$10 \mathrm{H}$ & 0.0006 & 0.0008 & 0.0013 & 0.0017 \\
$11 \mathrm{H}$ & 0.0004 & 0.0002 & 0.0008 & 0.0004 \\
$12 \mathrm{O}$ & 0.0024 & 0.0001 & 0.0051 & 0.0002 \\
$13 \mathrm{O}$ & 0.0007 & 0.0003 & 0.0015 & 0.0006 \\
$14 \mathrm{H}$ & 0.0007 & 0.0000 & 0.0015 & 0.0000 \\
$15 \mathrm{H}$ & 0.0009 & 0.0001 & 0.0019 & 0.0002 \\
$16 \mathrm{~N}$ & 0.1191 & 0.2208 & 0.2513 & 0.4659 \\
$17 \mathrm{C}$ & 0.1831 & 0.0605 & 0.3864 & 0.1277 \\
$18 \mathrm{C}$ & 0.0136 & 0.1117 & 0.0287 & 0.2357 \\
$19 \mathrm{C}$ & 0.0401 & 0.1081 & 0.0863 & 0.2281 \\
$20 \mathrm{C}$ & 0.0943 & 0.0039 & 0.1990 & 0.0082 \\
$21 \mathrm{H}$ & 0.0001 & 0.0000 & 0.0002 & 0.0000 \\
$22 \mathrm{C}$ & 0.0855 & 0.0079 & 0.1804 & 0.0166 \\
$23 \mathrm{H}$ & 0.0000 & 0.0001 & 0.0000 & 0.0002 \\
$24 \mathrm{C}$ & 0.1116 & 0.1488 & 0.2324 & 0.3140 \\
\hline
\end{tabular}
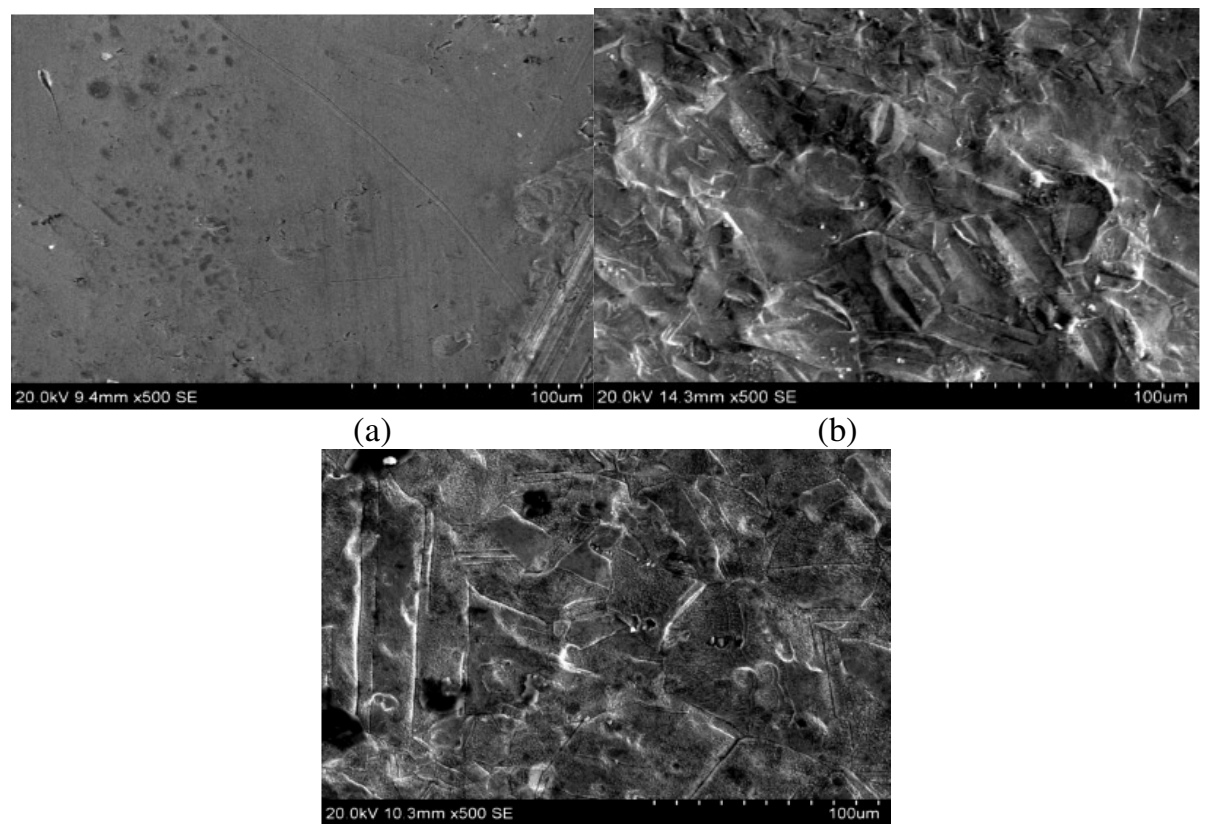

(c)

Figure 16. SEM micrographs of (a) copper metal before immersion in $1 \mathrm{M} \mathrm{HNO}_{3}$; (b) after immersion in $1 \mathrm{M} \mathrm{HNO}_{3}$, and (c) after immersion in $1 \mathrm{M} \mathrm{HNO}_{3}$ containing inhibitor molecule. 


\section{Scanning electron microscopy}

SEM was employed to explore additional information on the inhibition mechanism. The SEM micrographs of copper metal before and after exposure in $1 \mathrm{M} \mathrm{HNO}_{3}$ are shown in Fig. 16(a) and (b). These pictures clearly show that the surface was covered with high-density pits due to the exposure of copper in nitric acid. The influence of the addition of 200 ppm MBATD on copper metal in $1 \mathrm{M}$ $\mathrm{HNO}_{3}$ is shown in Fig.16(c). The micrograph shows no evidence of pitting. This may be due to the adsorption of inhibitor molecules around the pits formed on the specimens in the early stages of formation (initiation and propagation).

\section{Conclusions}

1) The inhibitor molecule shows very high inhibitive efficiency for copper in $1 \mathrm{M}$ $\mathrm{HNO}_{3}$.

2) The percentage inhibition efficiency increases with increase in concentration and decreases with temperature.

3) The adsorption of MBATD on copper surface follows Langmuir adsorption isotherm. The inhibitor molecules adsorb on the copper surface blocking the reaction sites. The surface area available for the attack decreases with increasing inhibitor concentrations.

4) Polarization studies reveal that MBATD acts as a mixed type inhibitor.

5) The corrosion inhibition efficiency of MBATD and the values $\mathrm{E}_{\text {HомO }}, \mathrm{E}_{\mathrm{LUMO}}$, $\mathrm{E}_{\mathrm{LUMO}}-\mathrm{E}_{\mathrm{HOMO}}$ and $\triangle \mathrm{N}$ of MBATD, calculated by DFT method, are correlated.

6) The molecular dynamics stimulation results reveal the adsorption of MBATD molecule on the copper surface.

\section{Acknowledgement}

The authors are grateful to Kerala State Council for Science Technology and Environment (KSCSTE) for financial support in the form of a major research project 018/SRSPS/2006/CSTE.

\section{References}

1. A. Fiala, A. Chibani, A. Darchen, A. Boulkamh, K. Djebbar, Appl. Surf. Sci. 253 (2007) 9347.

2. K.F. Khaled, Corros. Sci. 52 (2010) 3225.

3. F. Zucchi, G. Trabanelli, C. Monticelli, Corros. Sci. 38 (1996) 147.

4. $\quad$ S.A. Abd El-Maksoud, h.H. Hassan, Mater. Corros. 58 (2007) 5.

5. G. Singh, J. Telegad, E. Kalman, Paper 331 in 13th International Corrosion Congress, Melbourne, Australia (1996).

6. F .Mansfeld, Y. Wang, Paper No 41, in Corrosion'95 NACE (1995).

7. A.J. McMahon, D. Harrop, Paper No 32 in Corrosion' 95. NACE (1995).

8. C. Adamo, V. Barone, Chem. Phys. Lett. 330 (2000) 152.

9. M. Parac, S. Grimme, J. Phys. Chem. A 10 (2003) 6844. 
10. K.F. Khaled, Electrochim. Acta 53 (2008) 3484.

11. K.F. Khaled, Electrochim. Acta 54 (2009) 4345.

12. K.F. Khaled, M.A. Amin, Corros. Sci. 51 (2009)1964.

13. Y. Tang, X. Yang, W. Yang, Y. Chen, Rong Wan, Corros. Sci. 52 (2010) 242.

14. M. Adamek, Coll. Czech. Chem. Commun. 25 (1960) 1694.

15. W. Vreugdenhil, J.G. Haasnoot, J. Reedijk, A.L. Spek, Inorg. Chim. Acta 129 (1987) 205.

16. P.J. van Koningsbruggen, J.W. van Hal, R.A.G. de Graff, JG. Haasnoot, J. Reedijk, J. Chem. Soc. Dalton Trans. (1993) 2163.

17. M.J. Frisch, G.W. Trucks, H.B. Schlegel, G.E. Scuseria, M.A. Robb, J.R. Cheeseman,V.G. Zakrzewski, J.A. Montgomery Jr., R.E. Stratmann, J.C.Burant, S. Dapprich, J.M Millam, A.D. Daniels, K.N. Kudin, M.C. Strain, O. Farkas, J. Tomasi,V. Barone, M.Cossi, R. Cammi, B. Mennucci, C. Pomelli, C. Adamo, S. Clifford, J.Ochterski, G.A.Petersson, P.Y. Ayala, Q. Cui, K. Morokuma, D.K. Malick, A.D. Rabuck, K. Raghavachari, J.B. Foresman, J. Cioslowsk, J.V. Ortiz, B.B. Stefanov, G. Liu, A. Liashenko, P. Piskorz, I. Komaromi, R. Gomperts, R.L. Martin, D.J. Fox, T. Keith, M.A. Al-Laham, C.Y. Peng, A. Nanayakkara, C. Gonzalez, M.Challacombe, P.M.W. Gill, B.G. Johnson,W. Chen, M.W. Wong, J.L. Andres, M. HeadGordon, E.S. Replogle, J.A. Pople Gaussian 03, Revision B.05. Gaussian Inc., Pittsburg.(2003).

18. N. Lopez, F. Illas, J. Phys. Chem. B 102 (1998) 1430.

19. C. Lee, W. Yang, R.G. Parr, Phys. Rev. B 37 (1988) 785.

20. R.G. Parr, W. Yang, "DFT of atoms and molecules", Oxford University Press, Oxford (1989).

21. A. E. Reed, L.A. Curtiss, F. Weinhold, Chem. Rev. 88 (1988) 899.

22. A.D. Becke, J. Chem. Phys. 98 (1993) 5648.

23. F.de Proft ,J.M.L. Martin, P. Geerlings, Chem. Phys. Lett. 256 (1996) 400.

24. Y.M. Tang, X.Y. Yang, W.Z. Yang, Y. Chen, Rong Wan, Corros. Sci. 52 (2010) 246.

25. D.A. Jones, "Principles and Prevention of Corrosion", 2nd ed., Prentice Hall, NJ (1983).

26. K.F. Khaled, Sahar A. Fadl-Allah, B. Hammouti, Mater. Chem. Phys. 117 (2009) 151.

27. A. Chetouani, B. Hammouti, T. Benhadda, M. Daoudi, App. Surf. Sci. 249 (2005) 375.

28. B. El Mehdi, B. Mernari, M. Traisnel, F. Bentiss, M. Lagrenee, Mater. Chem. Phys. 77 (2002) 489.

29. R. Fuchs-Godec, Colloids Surf. A: Physicochem. Eng. Aspects 280 (2006) 130.

30. O. Benali, L. Larabi, Y. Harek, J. Saudi Chem. Soc. 14 (2010) 233.

31. Da-Quan Zhang, Qi-Rui Cai, Xian-Ming He, Li-Xin Gao, Gui Soon Kim, Mat. Chem. Phys. 114 (2009) 614.

32. F. Mansfeld, Corrosion 37 (1981) 301.

33. E. MacCafferty, Corros. Sci. 39 (1997) 243. 
34. M.S. Morad, Corros. Sci. 42 (2000) 1313.

35. C.H. Hsu, F. Mansfeld, Corrosion 57 (2001) 747.

36. R.G. Kelly, J.R. Scully, D.W. Shoesmith, R.G. Buchheit, "Electrochemical Techniques in Corrosion Science and Engineering", Marcel Dekker, Inc., New York (2002). p. 148.

37. M. Lebrini, M. Lagren, M. Traisnel, L. Gengembre, H. Vezin, F. Bentiss, Appl. Surf. Sci. 253 (2007) 9267.

38. M. Sahin, S. Bilgic, H. Y1lmaz, Appl. Surf. Sci. 1 (2002) 195.

39. E. Cano, J.L. Polo, A. La Iglesia, J.M. Bastidas, Adsorption 10 (2004) 219.

40. M. Lagrenee, B. Mernari, M. Bouanis, M. Traisnel, F. Bentiss, Corros. Sci. 44 (2002) 73.

41. M. Hosseini, S.F.L. Mertens, M.R. Arshadi, Corros. Sci. 45 (2003) 1473.

42. M.A. Amin, S.S. Abd El Rehim, H.T.M. Abdel-Fatah, Corros. Sci. 51 (2009) 882.

43. M. Bouklah, B. Hammouti, M. Lagrenee, F. Bentiss, Corros. Sci. 48 (2006) 2831.

44. A. Ostovari, S.M. Hoseinieh, M. Peikari, S.R. Shadizadeh, S.J. Hashemi, Corros. Sci. 10 (2009) 1016.

45. L. del Campo, R.B. Perez-Saez, L. Gonzalez-Fernandez, M.J. Tello, Corros. Sci. 51 (2009) 707.

46. E.A. Noor, A.H. Al-Moubaraki, Mater. Chem. Phys. 110 (2008) 145.

47. L. Larabi, Y. Harek, O. Benali, S. Ghalem, Prog. Org. Coat. 54 (2005) 256.

48. L. Larabi, O. Benali, Y. Harek, Mater. Lett. 61 (2007) 3287.

49. T. Szauer, A. Brandt, Electrochim. Acta 26 (2004) 1209.

50. N.M. Guan, L. Xueming, L. Fei, Mater. Chem. Phys. 86 (2004) 59.

51. J. Fang, J. Li, J. Mol. Struct.(THEOCHEM) 593 (2002) 179.

52. G. Bereket, E. Hur, C. Ogretir, J. Mol. Struct. (THEOCHEM) 79 (2002) 578.

53. P. Zhao, Q. Liang, Y. Li, Appl. Surf. Sci. 252 (2005) 1596.

54. R.G. Pearson, Nat. Acad. Sci. 83 (1986) 8440.

55. R.G. Pearson, Inorg. Chem. 27 (1988) 734.

56. I. Lukovits,E. Kalman, F. Zucchi, Corrosion 57 (2001) 3.

57. P.W. Ayers, M. Levy, Theor. Chem. Acta 103 (2000) 353.

58. P. Geerlings, F.De Proft, Int. J. Mol. Sci. 3 (2002) 276.

59. Y. Li, J.N.S. Evans, J. Am. Chem. Soc. 117 (1995) 7756.

60. K.F. Khaled, Appli. Sur. Sci. 255 (2008) 1811-1818.

61. K.F. Khaled, Mohammed A. Amin, J. Appl. Electrochem. 39(12) (2009) 2553. 